\title{
Effects of critical fluctuations of storage temperature on the quality of dry dairy product
}

\author{
A. G. Galstyan, ${ }^{1}$ A. N. Petrov, ${ }^{2}$ E. E. Illarionova, ${ }^{3}$ V. K. Semipyatniy, ${ }^{1 *}$ S. N. Turovskaya, ${ }^{3}$ A. E. Ryabova, ${ }^{1}$ \\ S. A. Khurshudyan, ${ }^{1}$ R. R. Vafin, ${ }^{1}$ and I. A. Radaeva ${ }^{3}$ \\ ${ }^{1}$ All-Russian Scientific Research Institute of Brewing, Non-Alcoholic and Wine Industry, 119021, Moscow, Russia \\ ${ }^{2}$ All-Russian Scientific Research Institute of Technology of Preservation, 142703, Vidnoye, Moscow, Russia \\ ${ }^{3}$ All-Russian Scientific Research Institute of Dairy Industry, 115093, Moscow, Russia
}

\section{ABSTRACT}

Whole milk powder (WMP) is a universal raw material component that can overcome the problem of seasonality of raw milk. It can be used to provide highnutritional products to remote areas experiencing a raw milk shortage. Its long shelf life depends on the conditions of storage and transportation, which are recommended to be carried out in a range from 0 to $10^{\circ} \mathrm{C}$. At higher temperatures, the quality of WMP deteriorates because of a substantial increase in the degradation of fat and protein fractions. A range of low negative temperatures for storage have not been systematically investigated. Previous studies have shown that freezing WMP results in protein denaturation, crystallization of lactose, and extraction of free fat, all of which reduce the quality characteristics of the product, including deterioration of solubility, quick rancidification, and microbiological changes. However, these previous studies did not simulate the possible situations of transportation and storage of milk powder at low negative temperatures that occur in practice. Given the volume of transportation, distances and climatic characteristics of transportation routes play an important role in WMP preservation. In this study, we simulated storage and transport of WMP at $-20^{\circ} \mathrm{C}$. The samples were periodically thawed to 10 and $20^{\circ} \mathrm{C}$ and examined for physicochemical, functional-technological, thermodynamic, microbiological, and organoleptic parameters. Based on our results, storage of WMP at $-20^{\circ} \mathrm{C}$ for $40 \mathrm{~d}$ did not have a significant effect on its qualitative characteristics. We observed some compaction of product structure and clustering or clumping, which was reversible by slight mechanical impact. Artificial contamination of the packaging surface with yeast and molds, followed by thawing of the samples, indicated

Received July 8, 2019.

Accepted August 22, 2019.

*Corresponding author: semipyatniy@gmail.com the absence of the contaminants, which was explained by possible redistribution of moisture in the system.

Key words: milk powder, storage requirement, longterm storage, evaluation criteria, abiogenic loss of quality

\section{INTRODUCTION}

Globalization of the world economy requires modifications of the traditional food manufacturing industry, including enlargement of production capacity, increase of sales of world brands, and unification of technologies and equipment (Godfray et al., 2010; FAO, 2011, 2018; Berners-Lee at al., 2018). An important part of modern production is the transportation of raw material over long distances, the duration of which may exceed a month. During transportation, raw material can cross several climatic zones with substantial differences in temperature and humidity of the environmental air. This problem exists both in transportation of raw materials within countries with a large territory (e.g., Russia, the United States, China, India) and in transcontinental transfers (Weber and Matthews, 2008; Hammond et al., 2015). According to online tracking of transport routes, transportation of milk powder to other continents is often practiced in the winter. Therefore, expanding our knowledge about quality loss due to the temperature of transportation is relevant worldwide, especially taking into account the ongoing market globalization. Moreover, even though the range of positive temperatures have been investigated, data on the effects of low negative temperatures during transportation is not systematized. Therefore, it is essential to study the processes of quality loss in food commodities during long-term transportation (Krasulia et al., 2015).

In the food industry today, solutions to similar problems are differentiated by particular product properties, which define the intensity of the processes and the declared shelf life. At the same time, most industrial 
solutions to stabilize quality suggest the redundancy of mechanical impact. A priori, the study of degradation processes depending on transport and storage conditions will minimize the loss of quality of finished products, which ranges from 20 to $40 \%$ (Blichfeldt et al., 2015; Chalak et al., 2016; Schanes et al., 2018).

In most countries, milk and dairy products are the most important food products. Compliance with special conditions during their transport and storage is an integral part of the technological chain from commodity (raw material) to dairy product to consumer (Valero et al., 2012; Aung and Chang, 2014; Krasulia et al., 2015).

All the factors mentioned above apply in full measure to milk powder. Currently, in accordance with the applicable Russian State Standard (RFATRM, 2015), further referred to as GOST 33629, shelf life and storage conditions are set by the product manufacturer. It is recommended to store whole milk powder (WMP) between $0^{\circ} \mathrm{C}$ and $10^{\circ} \mathrm{C}$ and at a relative humidity of not more than $85 \%$ for 8 to 12 mo, depending on the type of milk powder and packaging (Galstyan et al., 2016a).

The Codex Alimentarius Commission (CAC) developed and adopted a standard for milk and milk products (FAO, 1999), according to which the terms and conditions of storage of products are now standardized.

Taking into account the purpose of the product and supply in areas with undeveloped dairy cattle farming, WMP can move across a range of climatic zones during long-term transport. When WMP is transported in a covered, full metal railway carriage or container vehicle under the influence of the sun, the air temperature inside a compartment can reach $50^{\circ} \mathrm{C}$ in summer and $-30^{\circ} \mathrm{C}$ or below in winter. As well as these extremes of temperature, the likelihood of repeated critical fluctuations from negative to positive temperatures should also be considered. In practice, during summer in warmer regions, WMP is often stored at sub-zero temperatures, given that these conditions better maintain the quality of the product (Westergaard, 2004; Galstyan and Petrov, 2008; Dubova et al., 2011; Shukesheva et al., 2018). We monitored storage temperature fluctuations from 2013 to 2018 at 39 dairy enterprises that produced and processed milk powder. Plants were located in different climatic zones across the Russian Federation. Actual product temperature in winter did not drop below $-18.8^{\circ} \mathrm{C}$, and in summer the product reached $34.7^{\circ} \mathrm{C}$ for a brief period on several occasions. However, in accordance with standards of the Russian Federation, the storage temperature of milk powder should not exceed $10^{\circ} \mathrm{C}$.

The scientific and technical literature states that in case of critical violations of storage conditions, various degradation processes can occur in milk powder, causing changes in the composition and properties of the product, including defects detected organoleptically (Westergaard, 2004). For example, the most frequently occurring defects are the formation of lumps (physical defect); changes in color or reduction of solubility (chemical defect); the emergence of rancid, unclean, or stale flavor or odors (chemical, biochemical, and microbiological defects); and others (Stapelfeldt et al., 1997; Thomsen et al., 2005b; Al Mahdi et al., 2006; Rozycki et al., 2007; Semeniuc et al., 2008; Gaiani et al., 2011; Szulc et al., 2016). Degradation processes initiated during transport or storage of milk powder can be identified during storage of the processed product (Lipatov and Tarasov, 1985; Isleten and Karagul-Yuceer, 2006; Petrov et al., 2010; Galstyan et al., 2016b; Petrov et al., 2017). Such situations pose risks for manufacturers processing milk powder. Considering current levels of market globalization and cross-border cooperation, consequences may be critical for both producers and processors of dry milk. Thus, research in this area is warranted, especially given the lack of systematized information in the literature.

Therefore, the objective of this study was to investigate changes in properties of WMP stored at unregulated temperatures from $-20^{\circ} \mathrm{C}$ to $20^{\circ} \mathrm{C}$; this range was sufficient to allow analysis of dew point and areas with high humidity.

\section{MATERIALS AND METHODS}

In carrying out the research, we used standardized and generally accepted methods of research in the chemico-technological and microbiological control of dairy products, as well as original methods (Lipatov and Tarasov, 1985; Stapelfeldt et al., 1997; Merculova et al., 2009). For the purpose of research, 96 samples of WMP with a mass fraction of fat of 24.8 to $25.7 \%$ were prepared and stored at $-20 \pm 1{ }^{\circ} \mathrm{C}$. The samples were first analyzed according to the requirements of GOST 33629 (Tyopel, 2012). The choice of whole milk is justified by the fact that it considers the changes associated with the fat fraction of the product (Gorbatova, 2011; Petrov et al., 2017). We studied the effect of critical temperature fluctuations on the dynamics of physicochemical, microbiological, and organoleptic factors of WMP.

\section{Algorithm for Modeling Critical Temperature Fluctuations}

Milk powder samples of approximately equal mass were placed in sterile polymer containers of the same type (Figure 1). Containers with WMP frozen at -20 
$\pm 1^{\circ} \mathrm{C}$ were stored in the freezer for $40 \mathrm{~d}$, performing regular sampling for analysis. For monitoring purposes, similar samples of milk powder stored in a sealed package at $10 \pm 1^{\circ} \mathrm{C}$ were considered.

In the first stage, the analyzed samples were left at a temperature of $10 \pm 1^{\circ} \mathrm{C}$ and $20 \pm 1^{\circ} \mathrm{C}$ for 1,2 , and $4 \mathrm{~d}$ after removal from the climatic chamber, and we studied their physical, chemical, microbiological, and organoleptic characteristics. The absence of tangible changes in the samples at 1,2, and $4 \mathrm{~d}$ of acclimation process allowed to offer a thermal compensation duration to be equal to $1 \mathrm{~d}$. The subsequent samplings were carried out on d 20 and 40 of storage. For monitoring purposes, samples of WMP from the analyzed batches were examined, which were stored in hermetically sealed packages at $10 \pm 1^{\circ} \mathrm{C}$. The research scheme is shown in Figure 2.

To achieve the most accurate results of the analysis and determine a reliable duration of heating/cooling of the samples depending on the type of product and testing conditions, we proposed the following algorithm. The following assumptions were made in calculations for the required acclimation time of the samples under study: the plastic container was filled with product to the maximum (the gray area in Figure 1); the factor of mechanical ventilation was not considered and the thermophysical parameters of the container were not considered because of the thin walls $(0.2 \mathrm{~mm})$ and light weight.

Calculations were based on the following assumptions. The amount of heat needed for heating/cooling of a given mass of product $(Q)$ was determined by equation [1]:

$$
Q=\Delta T \cdot c \cdot m,
$$

where $\Delta T=T_{2}-T_{1}=$ temperature difference $\left({ }^{\circ} \mathrm{C}\right) ; c$ = heat capacity $\left(\mathrm{kcal} / \mathrm{kg} \cdot{ }^{\circ} \mathrm{C}\right)$; and $m=$ sample weight $(\mathrm{kg})$.

Then, heat flux through a cylindrical surface, ignoring wall thickness and assuming a constant heat flow rate intensity over the surface (only the surface area of the cylinder is considered), was determined by equations [2] and [3]:

$$
\begin{gathered}
\frac{\mathrm{d} Q}{\mathrm{~d} \tau}=S \lambda \Delta T, \\
S=2 \pi r l+2 \pi r^{2},
\end{gathered}
$$

where $\tau=$ time (h), $\lambda=$ thermal conductivity coefficient $\left(\mathrm{kcal} / \mathrm{m} \cdot \mathrm{h} \cdot{ }^{\circ} \mathrm{C}\right) ; S=$ surface area of the cylinder $\left(\mathrm{m}^{2}\right) ; r=$ radius of cylinder $(\mathrm{m})$, and $l=$ height of cylinder $(\mathrm{m})$.

The velocity of thermal equilibrium was determined by equation [4]:

$$
\frac{\mathrm{d} \Delta T}{\mathrm{~d} \tau}=-\frac{\mathrm{d} Q}{\mathrm{~d} \tau} \frac{1}{\mathrm{~cm}} \Delta T .
$$

Converting [2] and [4] gives

$$
\frac{\mathrm{d} \Delta T}{\mathrm{~d} \tau}=-\frac{S \lambda}{c m} \Delta T .
$$

By solving the obtained differential equation, we have an expression for thermal equilibrium from time:

$$
\Delta T(\tau)=\Delta T_{0} e^{-\frac{S \lambda}{c m} \tau},
$$

where $\Delta T_{0}=$ initial thermal equilibrium.

The temperature of the sample-environment system in time asymptotically tends to the thermal equilibrium. As a criterion for the end of the process, $\Delta T$ of $\pm 0.3^{\circ} \mathrm{C}$ was taken to be the error of modern environmental compensation chambers (climatic chambers). The results of calculations of required acclimation time for samples of WMP in several temperature ranges are presented in Figure 3.

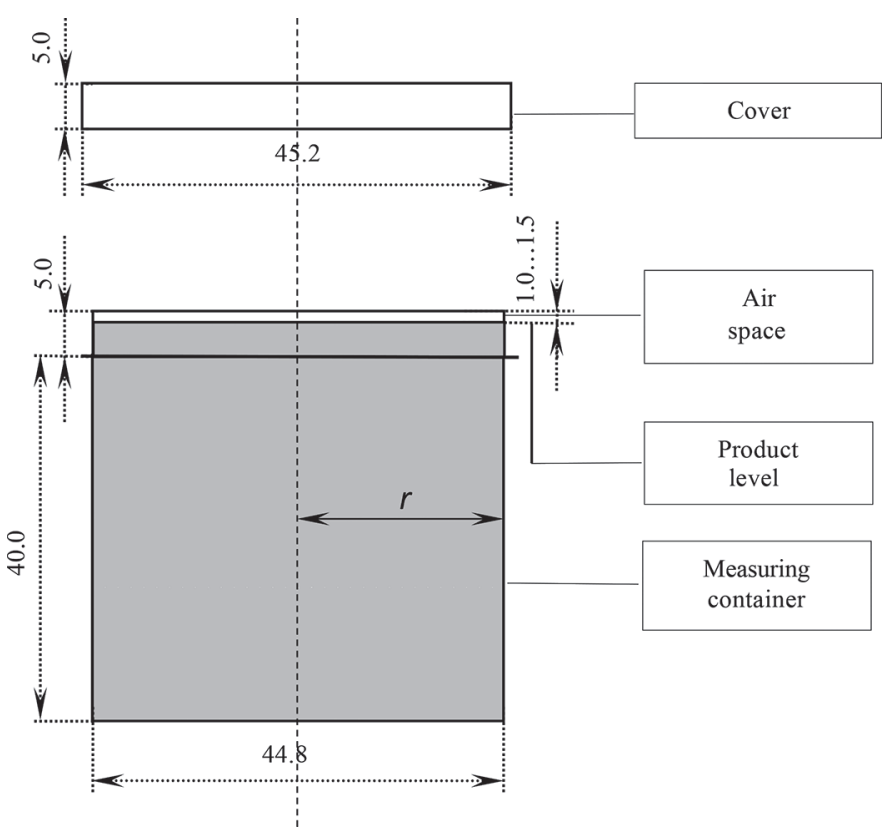

Figure 1. Cylindrical polymer container schematic and overall dimensions (in $\mathrm{mm}$ ); $r$ is the radius of the container. 


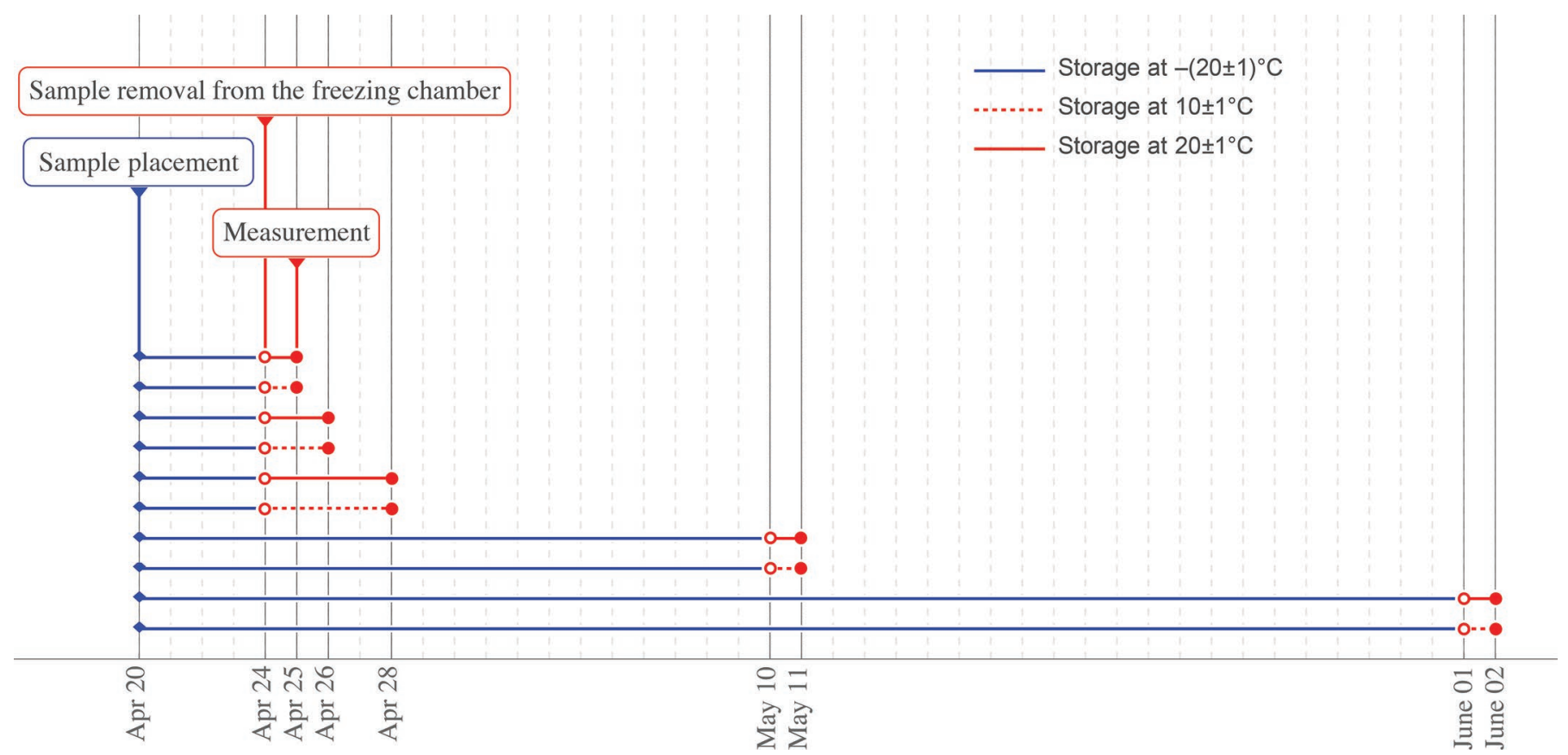

Figure 2. Experiment plan for identifying destructive processes in milk powder at critical storage temperature differences.

The following reference and experimental data were used for calculations of WMP: mass $m(\mathrm{~kg})=0.025$ \pm 0.003 ; coefficient of thermal conductivity $\lambda(\mathrm{kcal} /$ $\left.\mathrm{m} \cdot \mathrm{h} \cdot{ }^{\circ} \mathrm{C}\right)=0.160$; specific heat capacity $c\left(\mathrm{kcal} / \mathrm{kg} \cdot{ }^{\circ} \mathrm{C}\right)$ $=0.460 ;$ and radius of a cylinder $r(\mathrm{~m})=0.0023$.

We estimated that at maximum $\Delta T=40^{\circ} \mathrm{C}$ (from $-20^{\circ} \mathrm{C}$ to $20^{\circ} \mathrm{C}$ ), acclimation of samples should be performed for about $48 \mathrm{~h}$ for WMP. Later, the calculated data was tested experimentally. The amount of time spent on thermostatic control in the specified temperature was 29 to $31 \%$ lower than estimated, which is probably attributable to the mechanical ventilation factor. In practice, $\Delta T$ did not exceed $30 \mathrm{~h}$.

For preliminary modeling of values of dew point indicator, we devised an algorithm of its calculation under relevant software, taking into account external conditions. The algorithm incorporates the basic value of the atmospheric pressure of $101,325 \mathrm{~Pa}$ at $293.16 \mathrm{~K}$ $\left(20^{\circ} \mathrm{C}\right)$ and allows us to vary it.

To calculate water vapor pressure, we used the modified Wexler's equation [6], which in combination with Giland's coefficients, allows us to extend through extrapolation the temperature range of the area under research from -100 to $100^{\circ} \mathrm{C}$ :

$$
\ln P(T)=\sum_{i=1}^{7} g_{i} T^{i-3}+g_{8} \ln T,
$$

where $P=$ water vapor pressure over standard (distilled) water, $\mathrm{Pa} ; \mathrm{T}=$ temperature $(\mathrm{K}) ; g_{1}, g_{2}, \ldots$, $g_{\mathrm{i}}=$ Wexler's coefficient $\left[g_{1 \ldots 8}=\left(-2.8365744 \cdot 10^{3}\right.\right.$, $-6.028076559 \cdot 10^{3}, 1.954263612 \cdot 10,-2.737830188 \cdot 10^{-2}$, $1.6261698 \cdot 10^{-5}, \quad 7.0229056 \cdot 10^{-10}, \quad-1.8680009 \cdot 10^{-13}$, 2.7150305)].

Considering water vapor pressure over standard water at $0^{\circ} \mathrm{C}$ as $611.657 \mathrm{~Pa}$ and inputting Giland's deterioration factors ( $\alpha$ and $\beta$ ) adjusted for the International Temperature Scale 1990 (ITS-90) $[\alpha=$ $\left(3.62183 \cdot 10^{-4}, 2.60612 \cdot 10^{-5}, 3.86677 \cdot 10^{-7}, 3.82689 \cdot 10^{-9}\right)$ and $\beta=\left(-1.07604 \cdot 10,6.39874 \cdot 10^{-2},-2.63515 \cdot 10^{-4}\right.$, $\left.1.6725 \cdot 10^{-6}\right)$ ], we obtained deterioration factors depending on actual atmospheric pressure $\left(P_{a}, \mathrm{~Pa}\right)$ and ambient temperature $\left(t,{ }^{\circ} \mathrm{C}\right)$.

$$
\begin{gathered}
f\left(P_{a}, t\right)= \\
\operatorname{Exp}\left[\alpha(t)\left(1-\frac{P(t+273.16)}{P_{a}}\right)+e^{\beta(t)}\left(\frac{P_{a}}{P(t+273.16)}-1\right)\right], \\
\alpha(t)=\sum_{i=1}^{3} \alpha_{i} t^{i-1}, \beta(t)=\sum_{i=1}^{3} \beta_{i} t^{i-1} \\
P^{\prime}(T)=P(T) f\left(P_{a}, t\right),
\end{gathered}
$$




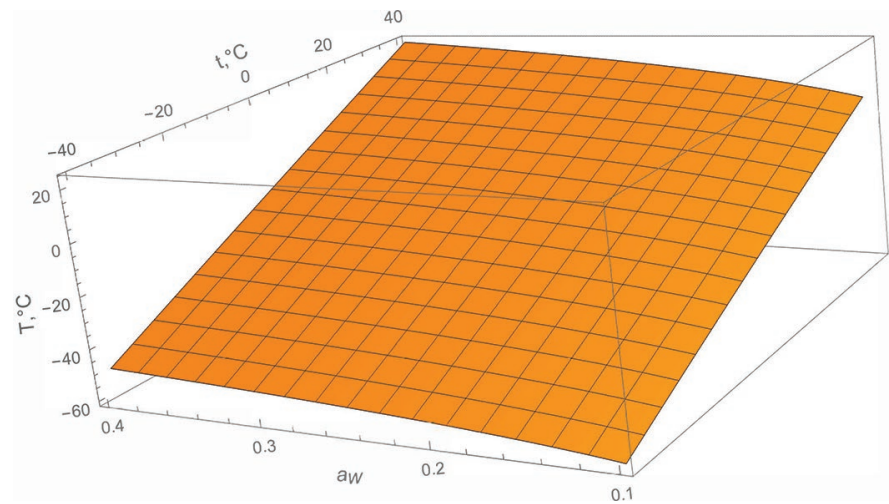

Figure 4. Theoretical results of dew point calculations demonstrat$\operatorname{ing} \mathrm{T}\left(\mathrm{t}, \mathrm{a}_{\mathrm{w}}\right)$ functional dependence, where $\mathrm{a}_{\mathrm{w}}$ is water activity (ranging from 0.1 to 0.4 to reflect relevant range in milk powder $\mathrm{a}_{\mathrm{w}}$ ); $\mathrm{t}$ is the dew point of reference water $\left({ }^{\circ} \mathrm{C}\right)$; and $\mathrm{T}$ is the dew point in the food product system $\left({ }^{\circ} \mathrm{C}\right)$.

where $P^{\prime}(T)=$ pressure adjusted for ambient conditions. For convenience, in coefficient formulas we assumed $0^{0}=1$.

The formula for calculating dew point $\left(T_{d},{ }^{\circ} \mathrm{C}\right)$ depending on saturation vapor pressure for pure water, taking into consideration coefficients of expression $c=\left(2.0798233 \cdot 10^{2},-2.0156028 \cdot 10,4.6778925 \cdot 10^{-1}\right.$, $\left.-9.2288067 \cdot 10^{-6}\right)$ and $d=\left(1, \quad-1.3319669 \cdot 10^{-1}\right.$, $\left.5.6577518 \cdot 10^{-3},-7.5172865 \cdot 10^{-5}\right)$ is presented in equation [9] (where $i$ is a summation index):

$$
T_{d}=\frac{\sum_{i=0}^{3} c_{i}(\ln P)^{i}}{\sum_{i=0}^{3} d_{i}(\ln P)^{i}} .
$$

Water activity $\left(\mathbf{a}_{\mathrm{w}}\right)$ index is the ratio of vapor pressure over a given material to vapor pressure over pure water at the same temperature (Thomsen et al., 2005a; Schuck et al., 2008; Strizhko et al., 2014). It was determined by sorption-capacitive method using a Hygrolab-3 device (Rotronic Company, Hauppauge, NY), with digital ventilated station AwVC-DIO (Rotronic) and by processing the results using HW3 software (Rotronic), according to

$$
P_{p r}=P \cdot \mathrm{a}_{\mathrm{w}},
$$

where $P_{p r}=$ water vapor pressure over product; and $\mathrm{a}_{\mathrm{w}}$ $=$ water activity of product.

Dependence of the dew point in a food system on $\mathrm{a}_{\mathrm{w}}$ and the dew point of pure water allowed us to obtain, from equations [6] and [7], vapor pressure over pure water; from equation [9], pressure over product; and from equation [8], the resulting temperature.

Graphic visualization of calculation results for a temperature range from -40 to $40^{\circ} \mathrm{C}$ is shown in Figure 4 , with a detailed range of $\mathrm{a}_{\mathrm{w}}$ from 0.2 to 0.3 , which is characteristic for dry dairy products. We developed software for optimization of calculations; the program

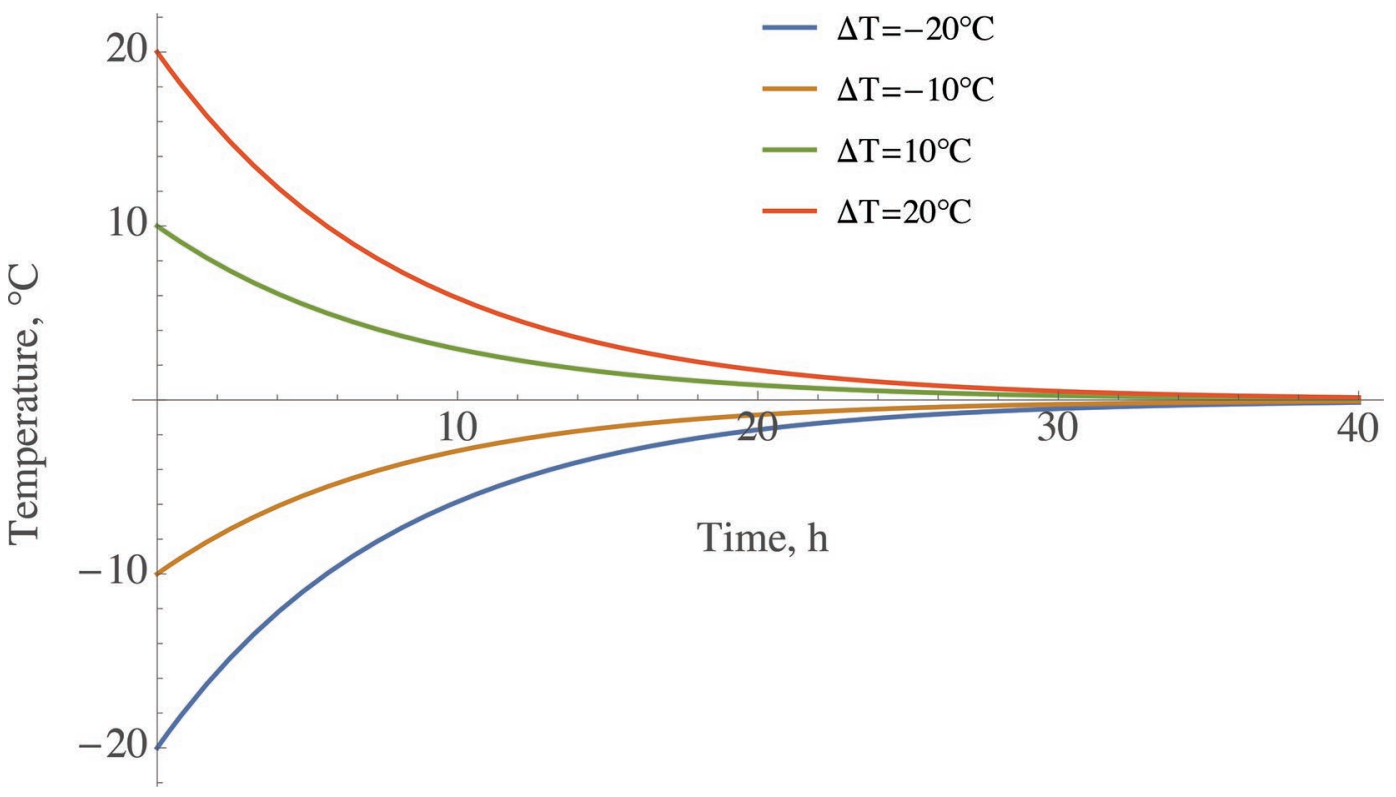

Figure 3. Estimated acclimation time for different changes in temperature $(\Delta \mathrm{T})$ of whole milk powder samples. 
zero $=273.16 ; \mathrm{pa}=101325 ;$

$\mathrm{g}=\left\{-2.8365744 \times 10^{3},-6.028076559 \times 10^{3}, 1.954263612 \times 10,-2.737830188 \times 10^{-2}\right.$, $\left.1.6261698 \times 10^{-5}, 7.0229056 \times 10^{-10},-1.8680009 \times 10^{-13}\right\}$;

g8 $=2.7150305$

loge $\left[T_{-}\right]:=\sum_{i=1}^{7} \mathrm{~g} \llbracket i \rrbracket T^{i-3}+\mathrm{g} 8 \log [T] ;$

aLow $=\left\{3.62183 \times 10^{-4}, 2.60612 \times 10^{-5}, 3.86677 \times 10^{-7}, 3.82689 \times 10^{-9}\right\}$;

aHigh $=\left\{3.53624 \times 10^{-4}, 2.93283 \times 10^{-5}, 2.61689 \times 10^{-7}, 8.58136 \times 10^{-9}\right\}$;

bLow $=\left\{-1.07604 \times 10,6.39874 \times 10^{-2},-2.63515 \times 10^{-4}, 1.6725 \times 10^{-6}\right\}$;

bHigh $=\left\{-1.07588 \times 10,6.32681 \times 10^{-2},-2.53689 \times 10^{-4}, 6.34052 \times 10^{-7}\right\}$;

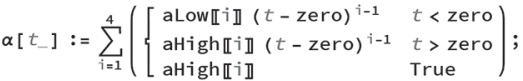

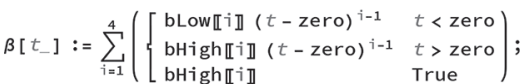

$f\left[P_{-}, t_{-}\right]:=\operatorname{Exp}\left[\alpha[t]\left(1-\frac{\operatorname{Exp}[\operatorname{loge}[t]]}{P}\right)+\mathbf{e}^{\beta[t]}\left(\frac{P}{\operatorname{Exp}[\operatorname{loge}[t]]}-1\right)\right] ;$

$c=\left\{2.0798233 \times 10^{2},-2.0156028 \times 10,4.6778925 \times 10^{-1},-9.2288067 \times 10^{-6}\right\} ;$

$d=\left\{1 .,-1.3319669 \times 10^{-1}, 5.6577518 \times 10^{-3},-7.5172865 \times 10^{-5}\right\}$;

$\operatorname{tr}\left[p_{-}\right]:=\frac{\sum_{i=1}^{4} \mathrm{c} \llbracket i \rrbracket \log [p]^{i-1}}{\sum_{i=1}^{4} \mathrm{~d} \llbracket i \rrbracket \log [p]^{i-1}} ;$

opts $=$ Sequence $[$ AppearanceElements $\rightarrow$ "InputField", Appearance $\rightarrow$ "Open"]

Manipulate [

Column [

\{Row [\{"Dew point in food product system, ${ }^{\circ} \mathrm{C}:$ ",

$\operatorname{tr}[f[\mathrm{P} p a, t+$ zero] $\operatorname{Exp}[\operatorname{loge}[\mathrm{T}+\mathrm{zero}]] \mathrm{A}]$ - zero $]]$,

Row[\{"Air temperature and atmospheric pressure enchancement factor: ", $f[\mathrm{Ppa}, \mathrm{t}+\mathrm{zero}]\}]\}]$

$\left\{\left\{T, \Theta\right.\right.$, Style ["Dew point (reference water), $\left.\left.{ }^{\circ} \mathrm{C} ", 15\right]\right\},-30,30$, opts $\}$,

$\{\{A, 0.1$, Style ["Water activity", 15] $\}, 0.1,1$, opts $\}$,

Delimiter,

$\left\{\left\{t, 20\right.\right.$, Style ["Air temperature, $\left.\left.{ }^{\circ} \mathrm{C} ", 15\right]\right\},-20,40$, opts $\}$,

$\{\{\mathrm{P}, 1$, Style ["Atmospheric pressure, atm", 15] $\}, 0.5,1.2$, opts $\}$

Figure 5. Software and interface for calculating the dew point.
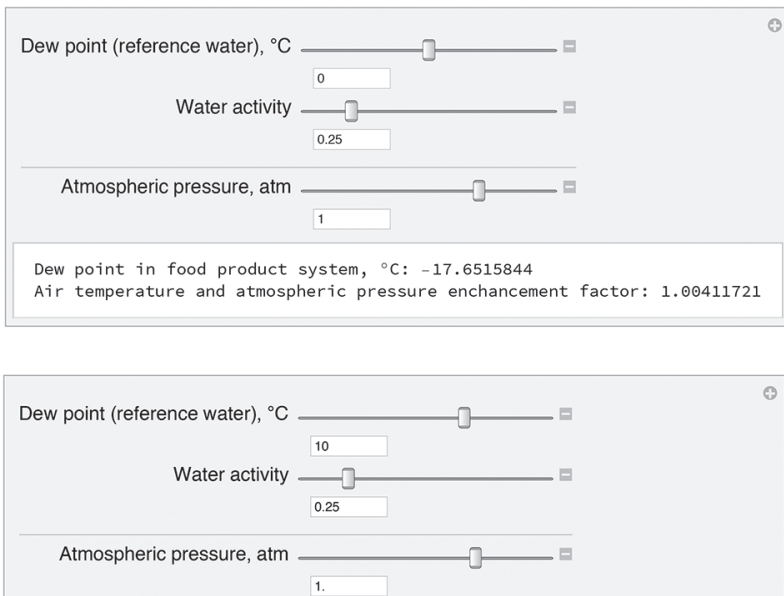

Dew point in food product system, ${ }^{\circ} \mathrm{C}$ : -9.07349893

Air temperature and atmospheric pressure enchancement factor: 1.00411721

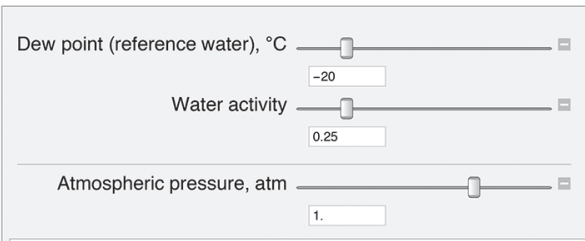

Dew point in food product system, ${ }^{\circ} \mathrm{C}$ : -34.999084

Air temperature and atmospheric pressure enchancement factor: 1.00411721

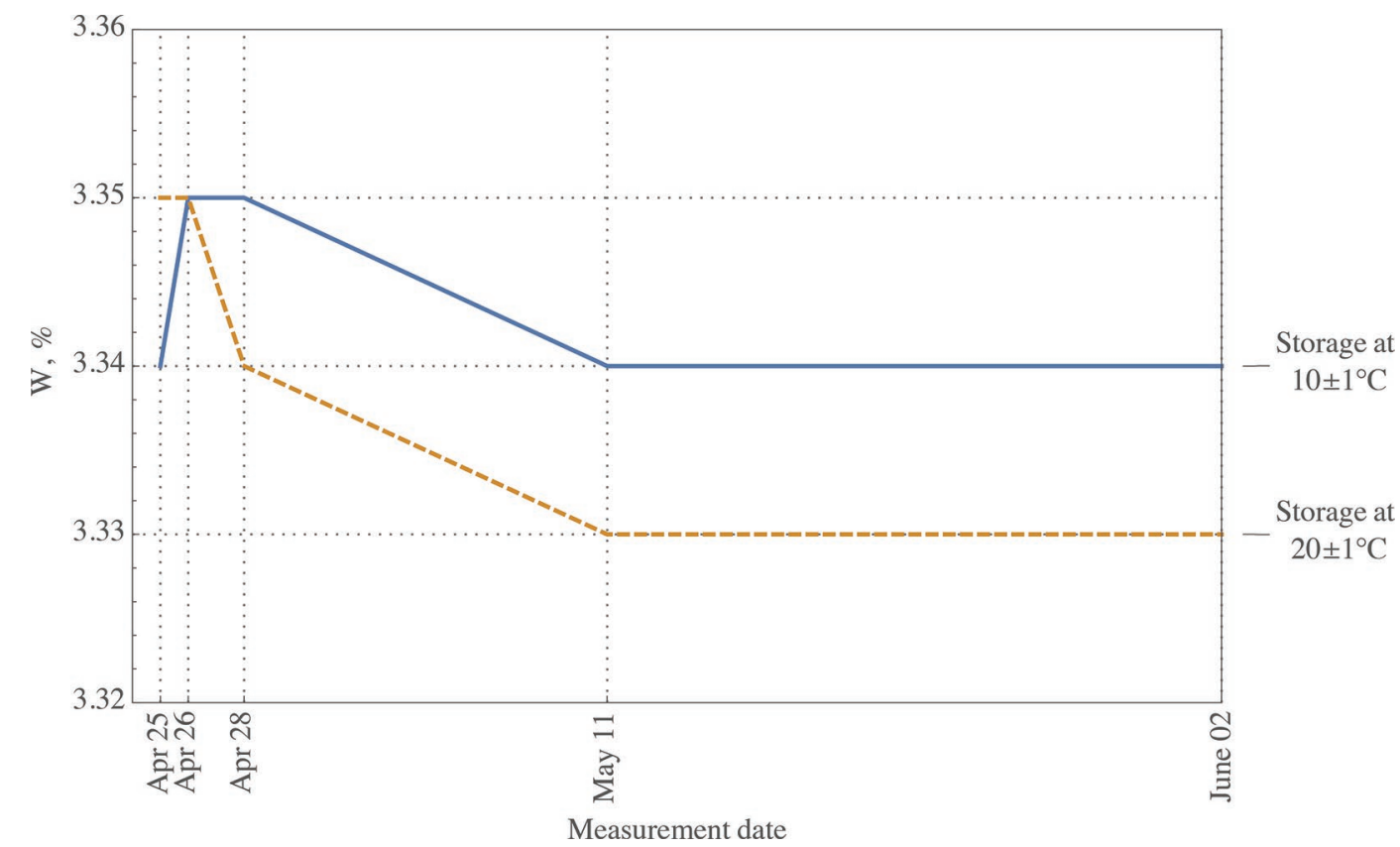

Figure 6. Changes in the mass fraction of moisture (W, \%) in experimental samples of milk powder. Relative standard deviation $(\mathrm{RSD})<1 \%$. 
and interface for 3 arbitrary calculations are presented in Figure 5.

Mass fraction of moisture was determined using an infrared thermogravimetric moisture meter MA50 (Sartorius, Göttingen, Germany). Granulometric composition was determined on Retsch Analytical Sieve Shakers AS200 Control (Retsch GmbH, Haan, Germany), which has microprocessor-controlled system of analysis control and Amplimatic and EasySieve processing software. The free fat mass fraction was determined by method of adsorption of destabilization fat on silica gel according to state standard (RFATRM, 2012). The method is based on adsorption of destabilization fat on silica gel, its subsequent elution with organic solvent, removal of solvent, and weighing the precipitated free (destabilization) fat. Microstructure of particles of milk was investigated by using near-field scanning optical microscope MIKMED-6 (LOMO PLC, St. Petersburg, Russia) by Micro-Analysis Pro software
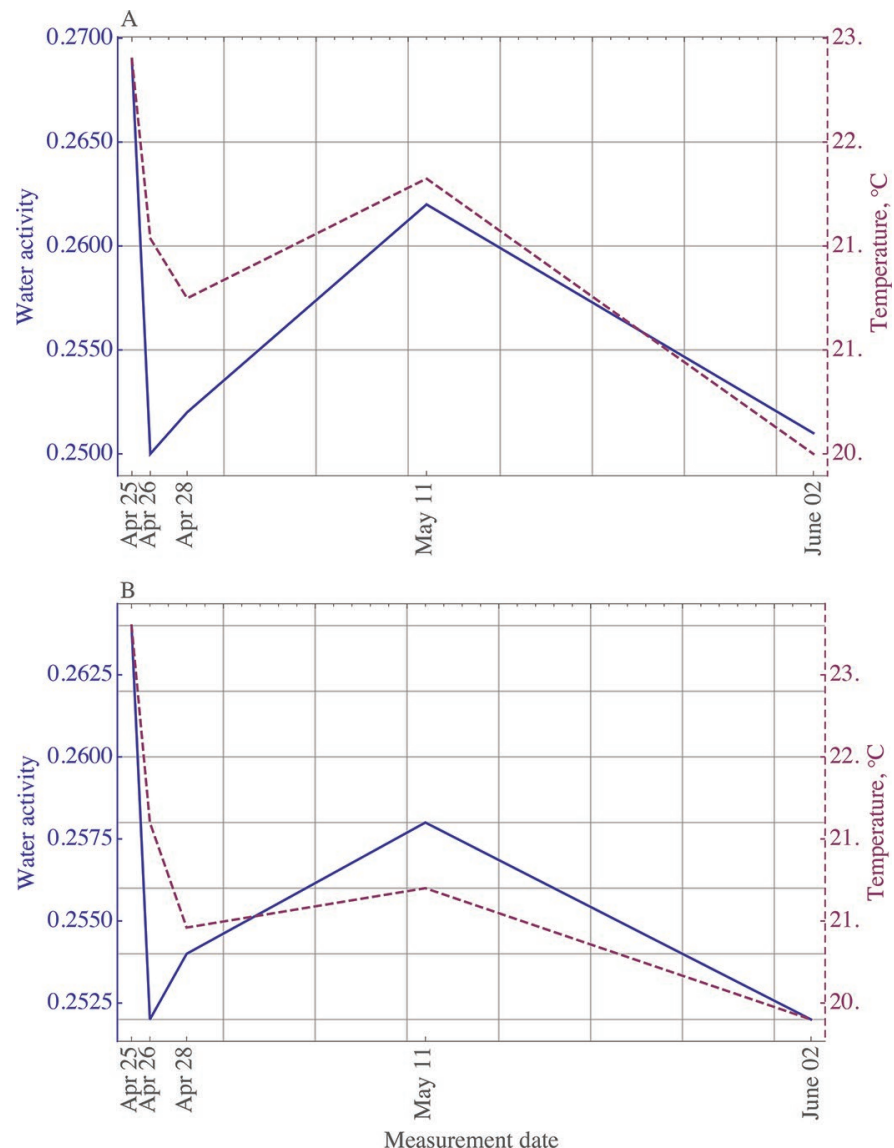

Figure 7. Changes in water activity $\left(\mathrm{a}_{\mathrm{w}}\right)$ in whole milk powder samples during storage at (A) $-10 \pm 1^{\circ} \mathrm{C}$ and (B) $-20 \pm 1^{\circ} \mathrm{C}$. Relative standard deviation (RSD) $<3 \%$. program (LOMO PLC). To assess the state of the fat phase under the microscope, we used a lipid staining method with an alcoholic solution of Sudan IV. To do this, milk powder was mixed with dye and the specimen was put under the microscope. The dye passes into the fat fraction and allows visualization of lines of globules and assessment of the presence of free fat.

\section{Microorganisms in WMP Samples}

Determination of colony count of yeasts and molds in the samples was carried out according to a state standard (RFATRM, 2013). The method is based on product seeding or product homogenate and (or) their dilutions in culture medium and identifying isolated microorganisms as molds and yeasts by characteristic growth on culture medium and by cell morphology.

The quantity of mesophilic aerobic and facultative anaerobic microorganisms (QMAFAnM) was determined according to state standard (RFATRM, 2014). The method is based on calculating the colonies of microorganisms growing on QMAFAnM solid culture medium at $30 \pm 1^{\circ} \mathrm{C}$ for $72 \mathrm{~h}$. Detecting bacteria of the coliform group is based on the ability of this group of microorganisms to ferment lactose in culture medium with gas and acid formation at $37 \pm 1^{\circ} \mathrm{C}$ for $24 \mathrm{~h}$. Colibacillus growth in liquid Kessler medium is confirmed by visually observed gas accumulation in the float.

Samples were taken from the entire surface of the container lid by using a sterile moistened cotton swab. For microbiological studies, a work pool was singled out, assuming contamination of the container lid with certain quantities and types of microorganisms, growth or suppression of which was evaluated after a one-time critical temperature fluctuation.

We grew yeasts and mold on slant agar at a constant temperature of $24 \pm 2^{\circ} \mathrm{C}$. Suspension was prepared by subsequent flushing of the biomass of cells with saline. The number of yeasts and molds was determined by suspension cell seeding in the Sabouraud agar. Tenfold dilutions were prepared until the number of cells on the jar lid was approximately 50 to $100 \mathrm{cfu} / \mathrm{cm}^{3}$.

\section{Statistical Analysis}

At each time point, 5 samples were analyzed for each experiment (moisture mass fraction, $a_{w}$, and QMAFAnM dynamics). All figures represent mean values, and an upper bound on relative standard deviation (RSD) for each figure is specified. A Student's $t$-test was performed to determine significance of the observed dynamics with threshold probability equal to 0.05. All statistical research was conducted using 


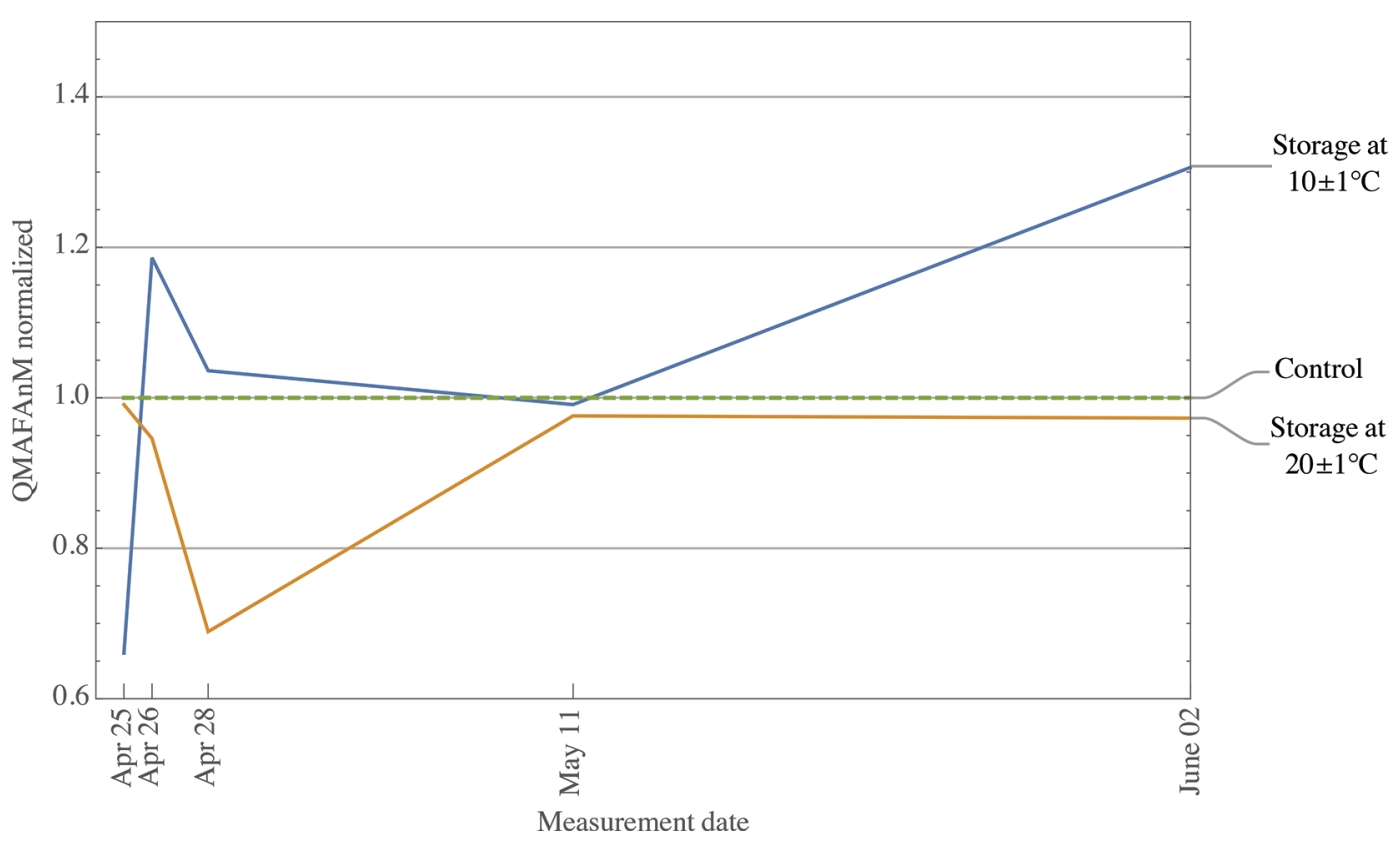

Figure 8. Changes in the quantity of mesophilic aerobic and facultative anaerobic microorganisms (QMAFAnM) in experimental samples relative to the control value. Data are normalized such that the QMAFAnM mean value of samples in a control group is equal to 1, and the relative standard deviation (RSD) of each data point is $<10 \%$.

Wolfram Mathematica software (Wolfram Research Inc., Champaign, IL).

\section{RESULTS AND DISCUSSION}

During this study, the normalized indicators of products under research did not undergo significant changes. We present partial detail of the obtained material for better visualization. According to our experimental plan (Figure 2), the dynamics of several milk powder indicators were studied.

Figure 6 shows data of moisture redistribution (W) in a closed volume of product. The data showed that changes in moisture in WMP were not significant $(P$ $>0.05)$ in the studied time range. The observed downward tendency is probably explained by redistribution of additional product moisture that entered its air environment during packaging.

The $\mathrm{a}_{\mathrm{w}}$ results at $10 \pm 1^{\circ} \mathrm{C}$ and $20 \pm 1^{\circ} \mathrm{C}$ are presented in Figure 7A and $\mathrm{B}$, respectively. Changes in $\mathrm{a}_{\mathrm{w}}$ further suggested $(P<0.05)$ the redistribution of moisture in the product.

To confirm the absence of moisture redistribution, we investigated the possibility of formation of areas with critical moisture content that could contribute to the growth of microorganisms. The results of QMAFAnM dynamics compared with control values are presented in Figure 8. We did not identify significant $(P>0.05)$ growth of microorganisms under the given conditions. Minor fluctuations are more related to the error of the method and different sampling points.

To confirm the absence of growth of microorganisms, we conducted several additional experiments. Specific numbers of molds and yeasts were applied to sterile lids and dried under lyophilic conditions. After drying, the milk powder package was covered by the lids in a manner that ensured no contact with the product, and the storage fluctuations shown in Figure 2 were implemented. We observed no quantitative changes in microorganism colony counts.

Based on our results, storage of WMP under the conditions described here that simulate potential temperature fluctuations during storage showed no degradation of samples with respect to physicochemical or microbiological characteristics. Visual inspection of the samples (Figure 9) showed that they retained the shape of the container after low-temperature storage, even within $1 \mathrm{~d}$ (Figure 9A), and when destroyed, they fragmented into lumps (Figure 9B). Control samples, which were not frozen and were stored at $10 \pm 1^{\circ} \mathrm{C}$, did not lose their flowability properties (Figure 9C and D) and dispersed with little effort.

To better understand of the causes of clumping, we measured the free fat content of control and thawed WMP samples. The typical microstructure of the samples is shown in Figure 10. Comparative microscopic 
A

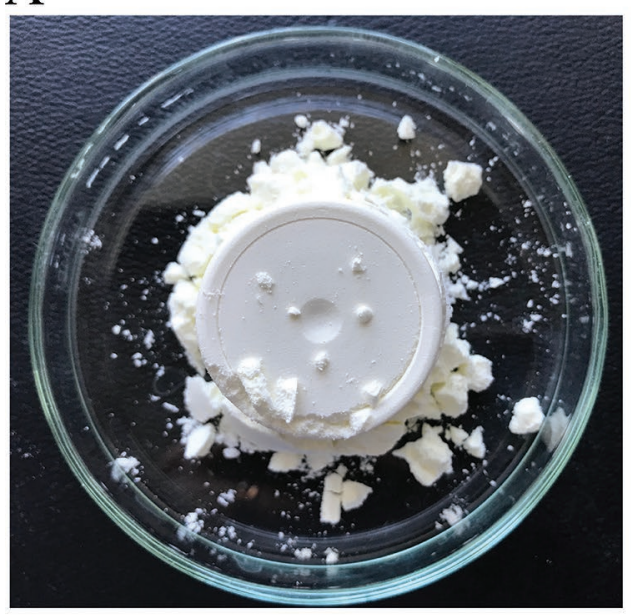

$\mathrm{B}$

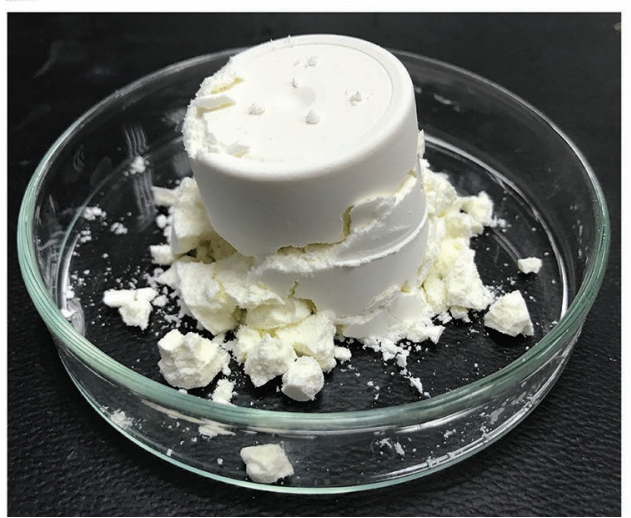

$\mathrm{C}$

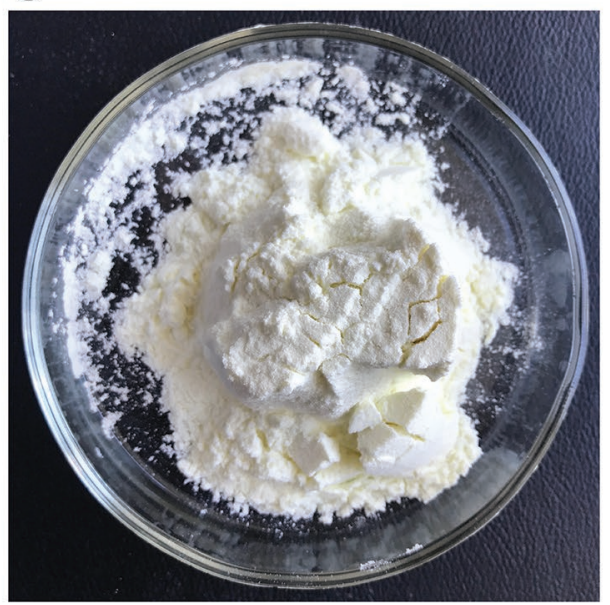

$\mathrm{D}$

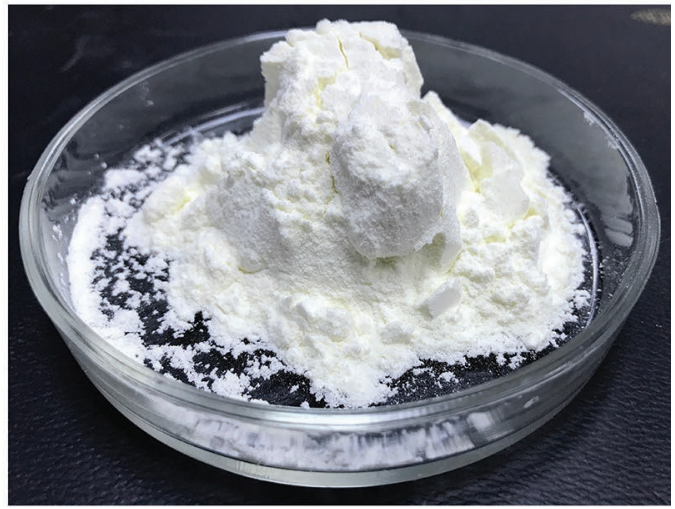

Figure 9. Structural differences in whole milk powder samples at low temperatures and recommended storage conditions. (A, B) Milk powder sample after $1 \mathrm{~d}$ of storage at $-20 \pm 1^{\circ} \mathrm{C}$, where B shows the sample after slight mechanical impact, showing the clumping effect. (C, D) Control sample stored at $10 \pm 1^{\circ} \mathrm{C}$ showed no signs of clumping before (C) or after (D) mechanical impact.

examination of samples before and after thawing (Figure $10 \mathrm{~A}$ and $\mathrm{B}$, respectively) showed an absence of release of free fat. Minor fat agglomeration was observed, which did not contribute to the decrease of dissolution intensity.

The organoleptic characteristics of the reconstituted samples of frozen and thawed milk powder were within regulated parameters, specifically consistency, color, and taste. We detected no clumping or storage defect indicators, such as rancid taste or foul odor. Subsequent studies of multiple (5 times) cycles of freezing and thawing of WMP revealed no negative changes in the quality of products.

\section{CONCLUSIONS}

Our results showed that storage of WMP at $20^{\circ} \mathrm{C}$ for $40 \mathrm{~d}$ did not affect quality or quantitative yield of reconstituted milk. We demonstrated that formation of a dew point following critical temperature fluctuations did not affect quality of WMP, whether the inner surface of the package was in contact with the product or separated from it by an air layer. We confirmed the lack of redistribution of moisture in packaged product volume by artificially contaminating the inner surface of the package with yeast and molds and showing an absence of yeast or mold growth after thawing the product. We detected no changes in technological and organoleptic characteristics of thawed WMP. We noted some compaction of the product and clumping, but this was reversible and the samples dispersed with little effort. These results confirmed that the acceptable thermal conditions of milk powder storage could be expanded to range from $-20^{\circ} \mathrm{C}$ to $10^{\circ} \mathrm{C}$. We demonstrated that multiple (5) freeze/thaw cycles did not alter the technological and quality characteristics of milk powder. 
A
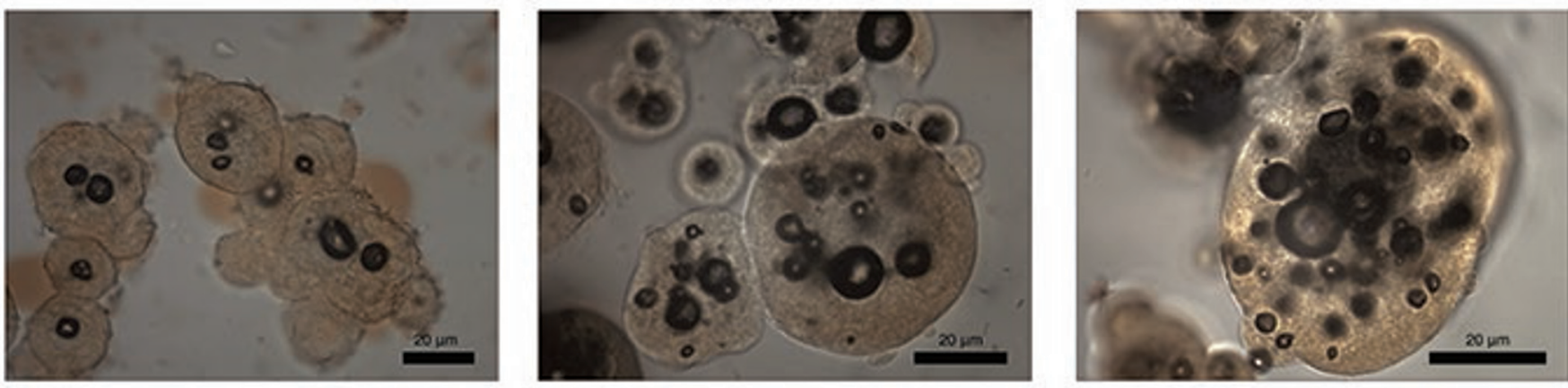

B
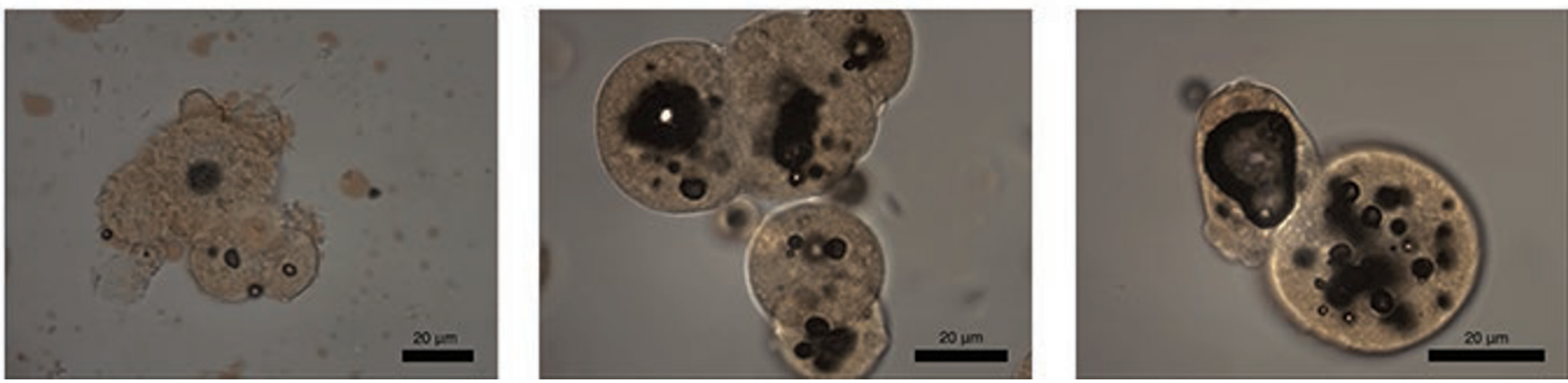

Figure 10. Samples of milk powder under the microscope before freezing (row A) and after thawing (row B). Scale bars $=20 \mu \mathrm{m}$.

\section{ACKNOWLEDGMENTS}

This research was not conducted under any specific grant. The authors declare that they have no conflicts of interest.

\section{REFERENCES}

Al Mahdi, R., A. Nasirpour, S. Banon, J. Scher, and S. Desobry. 2006. Morphological and mechanical properties of dried skimmed milk and wheat flour mixtures during storage. Powder Technol. 163:145-151. https://doi.org/10.1016/j.powtec.2006.01.012.

Aung, M. M., and Y. S. Chang. 2014. Traceability in a food supply chain: Safety and quality perspectives. Food Control 39:172-184. https://doi.org/10.1016/j.foodcont.2013.11.007.

Berners-Lee, M., C. Kennelly, R. Watson, and C. N. Hewitt. 2018. Current global food production is sufficient to meet human nutritional needs in 2050 provided there is radical societal adaptation. Elem. Sci. Anth. 6:52. https://doi.org/10.1525/elementa.310.

Blichfeldt, B. S., M. Mikkelsen, and M. Gram. 2015. When it stops being food. Food Cult. Soc. 18:89-105. https://doi.org/10.2752/ $175174415 X 14101814953963$.

Chalak, A., C. Abou-Daher, J. Chaaban, and M. G. Abiad. 2016. The global economic and regulatory determinants of household food waste generation: A cross-country analysis. Waste Manag. 48:418-422. https://doi.org/10.1016/j.wasman.2015.11.040.

Dubova, E. A., L. A. Buylova, and V. B. Kuznetsov. 2011. Determination of SMP availability. Dairy Indust. 3:84.

FAO (Food and Agriculture Organization of the United). 1999. Standard for Milk Powders and Cream Powder. CODEX STAN 2071999. FAO, Rome, Italy.

FAO (Food and Agriculture Organization of the United Nations). 2011. Global Food Losses and Food Waste: Extent, Causes and Prevention. FAO, Rome, Italy.
FAO (Food and Agriculture Organization of the United Nations) 2018. The Future of Food and Agriculture: Alternative Pathways to 2050. FAO, Rome, Italy.

Gaiani, C., P. Boyanova, R. Hussain, P. I. Murrieta, M. C. Karam, J. Burgain, and J. Scher. 2011. Morphological descriptors and color as a tool to better understand rehydration properties of dairy powders. Int. Dairy J. 21:462-469. https://doi.org/10.1016/j.idairyj 2011.02.009.

Galstyan, A. G., and A. N. Petrov. 2008. To the question of moisture sorption isotherms of dry dairy products. Storage Proc. Agric Raw Mater. 6:32-35.

Galstyan, A. G., A. N. Petrov, I. A. Radaeva, S. N. Turovskaya, V. V. Chervetsov, E. E. Illarionova, and V. K. Semipyatny. 2016a. Theory and Practice of Dairy Production. Publishing House Fedotov D.A., Moscow, Russia.

Galstyan, A. G., A. N. Petrov, and V. K. Semipyatniy. 2016b. Theoretical backgrounds for enhancement of dry milk dissolution process: Mathematical modeling of the system "solid particles - liquid". Foods Raw Mater. 1:102-109.

Godfray, H. C., J. R. Beddington, I. R. Crute, L. Haddad, D. Lawrence, J. F. Muir, J. Pretty, S. Robinson, S. M. Thomas, and C. Toulmin. 2010. Food security: The challenge of feeding 9 billion people. Science 327:812-818. https://doi.org/10.1126/science .1185383 .

Gorbatova, K. K. 2011. Fat globules shell structure. Dairy Indust. 2011(1):48-49.

Hammond, S. T., J. H. Brown, J. R. Burger, T. P. Flanagan, T. S. Fristoe, N. Mercado-Silva, J. C. Nekola, and J. G. Okie. 2015 Food spoilage, storage, and transport: Implications for a sustainable future. BioScience 65:758-768. https://doi.org/10.1093/ biosci/biv081.

Isleten, M., and Y. Karagul-Yuceer. 2006. Effects of dried dairy ingredients on physical and sensory properties of nonfat yogurt. J. Dairy Sci. 89:2865-2872.

Krasulia, O. N., V. V. Botvinnikova, and N. V. Popova. 2015. Formation of dairy products quality from the perspective of systems theory. Bulletin of South Ural State University. 1:191-198. 
Lipatov, N. N., and K. I. Tarasov. 1985. Reconstituted milk (theory and production practice of reconstituted milk products). Agropromizdat, Moscow, USSR.

Merculova, N. G., M. Y. Merculov, and I. Y. Merculov. 2009. Production Control in the Dairy Industry: A Practical Guide. Professia, Saint Petersburg, Russia.

Petrov, A. N., A. G. Galstyan, I. A. Radaeva, S. N. Turovskaya, E. E. Illarionova, V. K. Semipyatniy, S. A. Khurshudyan, L. M. DuBuske, and L. N. Krikunova. 2017. Indicators of quality of canned milk: Russian and international priorities. Foods Raw Mater. 5:151-161. https://doi.org/10.21603/2308-4057-2017-2-151-161.

Petrov, A. N., I. A. Radaeva, A. G. Galstyan, and S. N. Turovskaya. 2010. Canned milk production: Innovations in the formation of raw materials properties. Dairy Indust. 5:72-77.

RFATRM (Russian Federal Agency on Technical Regulating and Metrology). 2012. Milk and milk products. Methods for determination of free fat. No. 55332-2012. RFATRM, Moscow, Russia.

RFATRM (Russian Federal Agency on Technical Regulating and Metrology). 2013. Microbiology of Food and Animal Feeding Stuffs-Methods for the Detection and Colony Count of Yeasts and Moulds. No. 10444.12-2013. RFATRM, Moscow, Russia.

RFATRM (Russian Federal Agency on Technical Regulating and Metrology). 2014. Milk and milk products. Methods of microbiological analysis. No. 32901-2014. RFATRM, Moscow, Russia.

RFATRM (Russian Federal Agency on Technical Regulating and Metrology). 2015. Canned milk. Dry milk. Specifications. No. 33629 2015. RFATRM, Moscow, Russia.

Rozycki, S. D., M. S. Pauletti, S. C. Costa, A. M. Piagentini, and M. P. Buera. 2007. The kinetics of colour and fluorescence development in concentrated milk systems. Int. Dairy J. 17:907-915.

Schanes, K., K. Dobernig, and B. Gözet. 2018. Food waste mattersA systematic review of household food waste practices and their policy implications. J. Clean. Prod. 182:978-991. https://doi.org/ 10.1016/j.jclepro.2018.02.030.

Schuck, P., A. Dolivet, S. Méjean, and R. Jeantet. 2008. Relative humidity of outlet air: The key parameter to optimize moisture content and water activity of dairy powders. Dairy Sci. Technol. $88: 45-52$.
Semeniuc, C., R. Ancuta, D. Dumitras, C. Gus, M. Jimborean, S. Socaci, and C. Laslo. 2008. Physico-chemical changes in whole milk powder during different storage conditions. Bull. Univ. Agric. Sci. Vet. Med. Cluj-Napoca Agric. 65:400-404.

Shukesheva, S. E., Y. M. Uzakov, I. M. Chernukha, E. D. Nurmukhanbetova, Z. S. Nabiyeva, and A. B. Nurtaeva. 2018. Research to improve the quality of food products. Ser. Geol. Tech. Sci. 3:37-45.

Stapelfeldt, H., B. R. Nielsen, and L. H. Skibsted. 1997. Effect of heat treatment, water activity and storage temperature on the oxidative stability of whole milk powder. Int. Dairy J. 7:331-339.

Strizhko, M. A. Kuznetsova, A. Galstyan, A. Petrov, and A. Prosekov. 2014. Development of osmotically active compositions for milkbased products with intermediate humidity. Bull. Int. Dairy Fed. 472:41-48.

Szulc, K., J. Nazarko, E. Ostrowska-Ligęza, and A. Lenart. 2016. Effect of fat replacement on flow and thermal properties of dairy powders. Lebensm. Wiss. Technol. 68:653-658.

Thomsen, M. K., L. Jespersen, K. Sjøstrøm, J. Risbo, and L. H. Skibsted. 2005a. Water activity-temperature state diagram of amorphous lactose. J. Agric. Food Chem. 53:9182-9185.

Thomsen, M. K., L. Lauridsen, L. H. Skibsted, and J. Risbo. 2005b. Temperature effect on lactose crystallization, Maillard reactions, and lipid oxidation in whole milk powder. J. Agric. Food Chem. 53:7082-7090.

Tyopel, A. 2012. Milk Chemistry and Physics. Professia, Saint Petersburg, Russia.

Valero, A., E. Carrasco, and R. M. Garcia-Gimeno. 2012. Principles and methodologies for the determination of shelf-life in foods. In Trends in Vital Food and Control Engineering. Ayman Amer Eissa, ed. InTech, Rijeka, Croatia.

Weber, C. L., and H. C. Matthews. 2008. Food-miles and the relative climate impacts of food choices in the United States. Environ. Sci. Technol. 42:3508-3513. https://doi.org/10.1021/es702969f.

Westergaard, V. 2004. Milk Powder Technology: Evaporation and Spray Drying. 5th ed. Niro A/S, Soborg, Denmark. 